\title{
SERVIÇO PÓS-VENDA: A DIMENSÃO ESQUECIDA DO MARKETING
}

Claudia Buhamra Abreu

Mestre e Doutoranda pela EAESP/FGV e professora da Universidade Federal do Ceará

RESUMO:Tradicionalmente, o marketing tem negligenciado os serviços pós-venda. Sua preocupaçāo sempre foi com as atividades que antecedem a venda de um produto, e com a venda propriamente dita. Hoje, essa visāo está mudando. Ganha destaque o marketing de relacionamento, centrado nos serviços que podem ser oferecidos ao consumidor depois de efetuada a compra. Mas o conceito e a importância do serviço pós-venda ainda nāo foram devidamente internalizados pela maioria das organizaçōes brasileiras. Ainda está longe o entendimento entre vendedores e compradores, depois de consumada a venda. E os relatórios anuais do Procon confirmam essa realidade.

ABSTRACT: Traditionally, marketing has neglected the after-sales services. It has been worried about the activities before the sales of the products, and with the sale itself. Nowadays, this point of view is changing. More attention is given to the marketing of relationship - the aftermarketing - centered in the services that can be offered to the consumer after sale. But the concept and the importance of the affer-sales marketing wasn't completely internalized by the majority of brazilian companies yet. It is far the sense between salers and buyers, affer sale. And the Procon's annual report confirms this reality.

PALAVRAS-CHAVE: aftermarketing, serviço, treinamento, pós-venda.

KEY WORDS: aftermarketing, services, training, after-sale. 


\section{O RETRATO dOS SERVIÇOS PÓS-VENDA NO BRASIL}

Quem não tem uma história de decepção com serviços pós-venda para contar? Quem ainda não pronunciou a frase: "Na hora de vender, prometem tudo; depois...". Quantas pessoas já tiveram dificuldades de realizar uma troca de mercadoria porque era sábado - o único dia disponível para compras? Ou ganhou um presente $e$ não pôde trocar porque não tinha nota fiscal - já que presente não se dá com nota? Ou foi mal atendido na hora de pagar uma prestação do crediário - feito por causa de uma grande compra com um ótimo vendedor? Ou aborreceu-se com a assistência técnica daquele aparelho de TV - ainda na garantia?

O Procon, principal entidade de defesa do consumidor ligada à Secretaria Estadual de Justiça e Cidadania de São Paulo, recebeu 190 mil reclamações no ano de 1992 - um salto de $70 \%$ em relação aos três últimos anos. Isso dá uma média de 15 mil atendimentos por mês. São brigas contra fabricantes de produtos e serviços, públicos e privados. E sempre depois da compra ${ }^{1}$.

Anualmente, o Procon é obrigado, por lei, a divulgar a temida relação das empresas com mais reclamações na entidade. $\mathrm{Na}$ primeira semana de abril de 1995, a Coordenadoria de Proteção e Defesa do Consumidor de São Paulo, que atende a $50 \%$ das reclamações de todo o país, divulgou o balanço do ano anterior: o número de queixas dobrou. A cada dia aparecem 1.400 novos casos de consumidores para serem resolvidos. Os Estados da Bahia, do Rio de Janeiro e do Paraná fizeram o mesmo. Só em São Paulo a listagem incluiu 2.016 empresas, algumas grandes e bem conhecidas como a
Fiat, a Volkswagen a Coca-Cola e a Sharp ${ }^{2}$.

Se por um lado esses dados demonstram que o consumidor brasileiro não está tão passivo na defesa de seus direitos, por outro revela que as empresas brasileiras, na sua maioria, não estão muito preocupadas em atender às expectativas dos seus consumidores. Para elas, o que ocorre depois da compra não merece tanta atenção.

O marketing de conquista e promoção continua dominando, enquanto atividades de serviços são subempregadas, colocadas em níveis inferiores, vistas estritamente como centros de custos e tidas como secundárias na estratégia empresarial competitiva. "A medida que amadurecemos em uma sociedade mais móvel, industrializada e tecnocrática, surge uma distinção entre a venda e as atividades pós-venda... Relegamos a segunda metade da venda a departamentos de reclamações, de serviços e de garantias"3.

$\mathrm{Na}$ verdade, os empresários parecem não perceber que os serviços constituem o grande diferencial de um negócio. $O$ consumidor não tem uma clara distinção entre produto e empresa. Os serviços são lembrados e comentados, sejam eles bons ou ruins, e as imagens positivas de confiança, familiaridade e bons serviços ainda determinam a preferência do consumidor.

Não deve causar surpresa que os profissionais liberais de áreas como direito, medicina, arquitetura, consultoria, investimentos e propaganda sejam categorizados $\mathrm{e}$ recompensados pelo nivel de relacionamento com os clientes. Esses relacionamentos, como quaisquer outros bens, podem valorizarse ou depreciar-se. Sua manutenção e realce não são uma questão de boas maneiras, relações públicas, tato, encanto, elegância ou manipulação, dependendo de administração e não apenas de marketing. A administração de relacionamento transcende os limites do marketing,
1. PAULINA, Iracy. Este é o defensor número 1 dos consumidores. Veja SP, $1^{\circ}$ set. 1993, p. 10-13.

$2 . \quad$ Comprando Problemas. Veja, 5 abr. 1995, p. 9293.

3. VAVRA, Terry G. Marketing de relacionamento - aftermarketing, São Paulo:Atlas, 1993. 
4. LEVITT, Theodore. A imaginação do marketing. São Paulo: Atlas, 1985

5. ALBRECHT, Kart. Revolução nos servicos: como as empresas podem revolucionar a maneira de tratar os seus clientes. São Paulo:Pioneira, 1992.

6. VAVRA, Terry G. Op. cit.

7. LEVITT, Theodore. Op. cit exigindo programas de manutenção, investimento, melhoria e também substituição ${ }^{4}$.

Algumas empresas já têm programas formais destinados a realçar as relações com seus clientes, que podem se caracterizar por seu caráter passivo ou ativo. Quando a empresa participa ativamente, ela se antecede ao cliente para saber o nível de satisfação com o produto ou serviço adquirido. Nesse caso, a empresa costuma ter um padrão mais eficaz de serviço pós-venda. Já as que atuam de forma passiva, ficam esperando as chamadas dos clientes. Nessa situação, a empresa corre o risco de cometer mais erros, $\mathrm{e}$ o cliente, de ser mal atendido.

Albrecht ${ }^{5}$ apresenta sete posturas que são consideradas os pecados dos serviços que as empresa cometem quando são procuradas por um cliente para esclarecimentos ou reclamações:

- apatia: atitude de pouco caso da parte da pessoa responsável pelo contato com o cliente;

- dispensa: procurar livrar-se do cliente desprezando sua necessidade ou seu problema;

- frieza: uma espécie de hostilidade gélida, rispidez, tratamento inamistoso, desatenção ou impaciência com o cliente;

- condescendência: tratar o cliente com uma atitude paternalista;

- automatismo: o funcionário mecanizado não demonstra calor ou individualidade;

- livro de regras: colocar as normas da organização acima da satisfação do cliente, sem dar liberdade ao funcionário que presta o serviço para abrir exceções ou usar o bom senso.

Muitas vezes, a busca de informação por parte do consumidor, após ter efetuado alguma compra, tem origem na necessida- de de reduzir a dissonância cognitiva - 0 reconhecimento mental que alguém comprou algo que pode não ter sido a alternativa mais inteligente ou mais racional. A necessidade do cliente em assegurar a certeza pós-compra é algo tão forte que não pode ser negligenciado pelo vendedor. Existe valor real em falar a um cliente após a compra de um produto ou serviço para assegurar-lhe que sua compra foi inteligente e que seu dinheiro foi bem aplicado ${ }^{6}$.

Um outro fator que requer das empresas fabricantes maior atenção na administração dos serviços após a venda dos seus produtos é a multiplicação dos canais de distribuição e, principalmente, dos intermediários. À medida que cresce a distância entre o fornecedor e o cliente final, o controle das empresas produtoras sobre as condições de venda e da oferta do serviço pósvenda diminui. Os fabricantes mais atentos movimentam-se em direção a seus usuários finais, mas, na maioria das vezes, essa distância permite aos fabricantes menos market-oriented diminuírem seu sentimento de obrigação em relação aos clientes, bem como justificar psicologicamente a maneira como eles são (mal) tratados.

Levitt ${ }^{7}$ afirma que vender é manter um relacionamento. E é preciso atenção especial ao que caracteriza singularmente um relacionamento: o tempo. A esse respeito, a teoria econômica de "oferta e procura" é totalmente falsa. Ela presume que o trabalho do sistema econômico pouco depende do tempo e ignora as interações humanas - uma transação de vendas instantânea, isolada, que se consuma na interseção de oferta e demanda. Isso nunca foi assim. E o é cada vez menos à medida que se intensificam a complexidade crescente do produto $e$ as interdependências das instituições do sistema industrial. 
Um cliente satisfeito gera muitos outros. Da mesma forma, um cliente insatisfeito tira da empresa clientes potenciais e, em alguns casos, já efetivos. Portanto, deve-se aumentar os esforços de marketing para os clientes existentes. Eles demonstram alto grau de lealdade quando compram pela segunda vez, por nenhuma outra razão maior de familiaridade e prazer ${ }^{8}$.

\section{PÓS-MARKETING OU MARKETING PÓS-VENDA?}

Quando a organização objetiva a conquista de novos clientes, os clientes atuais freqüentemente são negligenciados; seu valor para a empresa é esquecido, pois sua contribuição para o lucro é dada como certa. A organização presume que a satisfação desse cliente continuará sempre e, quando esses clientes deixam de ser fiéis, a mudança de preferência é justificada racionalmente pela empresa: "Não podemos agradar a todos" $"$.

No entanto, essa é uma visão míope da realidade. Vários estudos econômicos mostram que o valor de um cliente para uma empresa cresce e seus custos caem durante sua permanência com ela. À medida que as compras de um cliente aumentam, os custos operacionais da empresa declinam. O limite de crédito inicial não precisa ser renovado. Assim que a empresa ganha mais confiança no cliente passa a atendêlo melhor. No decorrer do tempo, à medida que o cliente começa a confiar nos serviços que recebe, fica mais disposto a comprar com o cartão de crédito da empresa, evitando o uso de outros cartões de crédito com características e políticas desconhecidas $^{10}$.

Existem, ainda, outros benefícios menos concretos para manter clientes. Por exemplo, eles proporcionam propaganda gratuita. A comunicação boca a boca, muitas vezes, é mais eficaz do que a propaganda paga. Por todas essas razões, a luta da empresa deve ser não apenas para aumentar o número de clientes mas para aumentar as vendas por clientes, pois o valor real de um cliente permanece durante toda sua vida com a empresa.

O cuidado e a atenção da empresa em manter seus clientes é hoje denominado aftermarketing (pósmarketing) porque aplica princípios de marketing aos clientes após eles terem com-

prado bens ou serviços de uma empresa. O pós-marketing tem como objetivos ${ }^{11}$ :

- manter clientes satisfeitos após a compra;

- aumentar a probabilidade de os clientes atuais comprarem novamente o produto ou a marca da mesma empresa em futuras ocasiões;

- aumentar a probabilidade de que os clientes atuais comprarão outros produtos da mesma empresa (um produto ou linha de produtos complementares) em vez de procurarem concorrentes quando necessitarem de tais produtos;

- reconhecimento dos clientes como indivíduos;

- deixar os clientes conscientes de que estão sendo cuidados.

Para atingir esses objetivos, o pós-marketing é manifestado em muitas diferentes atividades de marketing, todas elas enfocadas em clientes atuais ${ }^{12}$.

- identificação da base de clientes;

- pesquisa para conhecimento de suas necessidades e expectativas;

- mensuração repetida da extensão da satisfação dos clientes pelos produtos ou serviços atuais;

- fornecimento de canais de comunicação amplos;

- demonstração ativa de sentimentos de reconhecimento a eles.
8. Coopers \& Lybrand Deloitte. The discerning consumer - myth or reality. A study of consumer behaviour and its strategic implications for Retail Financial Service. Texto de Solutions for Business da London Business School London, 1992, p. 1-20.

9. VAVRA, Terry G. Op. cit.

10. Idem.

11. Idem, ibidem.

12. Idem, ibidem. 
Assim, considerando que essas são todas atividades de marketing, torna-se necessário questionar o termo aftermarketing (pós-marketing), na medida em que ele isenta os profissionais de marketing da responsabilidade de cuidar das atividades referentes ao pós-compra. Em vez do termo aftermarketing seria mais adequada a expressão marketing aftersale (marketing pós-venda) englobando toda uma linha de serviços de acompanhamento da satisfação do cliente após a compra, por meio de um database marketing, tendo em vista a recompra. O que vem depois da venda também é marketing, e talvez seja o momento mais importante e decisivo para a imagem da empresa no mercado.

Seguindo essa linha, Berry ${ }^{13}$ sugeriu recentemente a modificação do composto de marketing para o seguinte:

- produto: qualidade, confiabilidade, características;

- preço: preço cobrado, condições de preço e oferta de preço;

- distribuição: acessibilidade aos bens ou às instalações do fornecedor e acessibilidade do cliente;

- promoção: propaganda pré-venda, publicidade e promoções de vendas;

- comunicações com o cliente: programas de comunicação pós-venda, (revistas próprias, eventos etc.) código 0800 (discagem direta gratuita) a serviço de atendimento de reclamações e de cumprimentos aos clientes;

- satisfação do cliente: monitoramento das expectativas do cliente e a satisfação de-

13. Berry. In: VAVRA, Op. cit.

14. BERRY, Leonard L. \& PARASURAMAN, A. Serviços de marketing - competindo através da qualidade. São Paulo: Maltese-Norma, 1992.

15. LEVITT, Theodore. Op. cit. 16. Idem, ibidem. de clientes de "situações de recuperação do serviço" e afirmam que são oportunidades de ouro para superar as expectativas dos clientes. Thomas R. Elsman, administrador de planejamento estratégico da divisão de serviço para o cliente da DuPont, explica isso muito bem: "Conforme forem surgindo as emergências e as queixas, trate-as com empatia e determinação, pois um serviço notável nessa área será encarado como o quilômetro extra e pode transformar uma coisa negativa em positiva". Mesmo assim, muitas empresas estão mal-equipadas para serem excelentes na recuperação do serviço.

A recuperação do serviço é um momento que exige da empresa muita dedicação, principalmente porque, em geral, os clientes têm mais expectativas e menos tolerância durante esse momento do que durante os serviços de rotina.

"Sua próxima venda, próxima idéia, próximo sucesso dependem muito dos seus relacionamentos externos. Um bom relacionamento é um ativo importante. Podemos investir em relacionamentos e nos servir deles. Fazemos tudo isso, porém raramente o percebemos e quase nunca administramos o relacionamento. $E$, no entanto, o bem mais precioso de uma empresa está em suas relações. Não se trata de quem você conhece, mas como você é conhecido dele. Esta é uma função da natureza do seu relacionamento com eles, e depende de como esse relacionamento foi administrado"15.

\section{ORIENTANDO A EMPRESA PARA UM RELACIONAMENTO PÓS-VENDA}

O professor Theodore Levitt ${ }^{16}$, analisando a administração do relacionamento entre empresa e consumidor, faz uma analogia interessante. Para ele, a venda consuma o namoro; depois, começa o casamento. O quanto o casamento tem de bom depende do quão bem o relacionamento é administrado pelo vendedor. Isso determina se haverá negócios continuados e se 
serão expandidos, ou haverá problemas e divórcio. Em outras palavras, aumentamse os custos ou os lucros. Em alguns casos o divórcio é impossível; por exemplo quando uma grande obra de construção ou instalação está em andamento, restando um casamento cheio de encargos e caro, que macula a reputação do vendedor. As empresas podem evitar problemas e realçar sua posição reconhecendo, logo de início, a necessidade de administrar seu relacionamento com os clientes. Para o vendedor, a venda é o fim de um processo; para o comprador, é o início. Essa visão exige do futuro comprador, nova orientação e nova estratégia. $\mathrm{O}$ marketing tradicional, por si só, já não é suficiente.

Segundo Vavra ${ }^{17}$, as razões mais comuns que levam os clientes a abandonar uma empresa, são as seguintes:

- insatisfação com o produto, entrega, instalação, serviços ou preço. Mesmo que um cliente aceite as desculpas pelo atraso na entrega, embalagem inadequa$\mathrm{da}$, até por receber produtos de qualidade inferior, é improvável que, no mundo competitivo de hoje, em face das situações acima, ele permaneça leal à empresa;

- dificuldade de lidar com reclamações. Essa é uma situação em que um único incidente pode levar um cliente a abandonar a empresa. Se o cliente sente que sua reclamação foi ignorada, minimizada ou mal solucionada, existem chances de que ele procure outro fornecedor. Quaisquer desentendimentos com os vendedores aumenta, substancialmente, a possibilidade de se perder um cliente;

- desaprovação de mudanças. Os relacionamentos com clientes são vulneráveis a qualquer mudança de preço, políticas ou vendedores. Alguns clientes podem ficar tão irritados que param de comprar imediatamente;
- insatisfação com o tratamento. Freqüentemente, os clientes atuais não recebem a atenção e cortesia que merecem. Sua familiaridade leva-os a serem tratados de maneira imprópria (muitas vezes rude). Esse é um erro capital: todos os clientes devem ser tratados com igual respeito;

- novos funcionári-os ou novas políticas da empresa. Mudanças na situação do cliente podem romper o relacionamento deste com a empresa, sem que ela tenha cometido nenhuma falha. A melhor defesa é ficar alerta a tais possibilidades e tentar antecipar e neutralizar seus impactos;

- aceitação de uma oferta concorrente. Nenhum cliente, não importa sua fidelidade, está garantido além do último pedido que assinou. O concorrente está sempre alerta e, às vezes, leva-o embo$\mathrm{ra}^{18}$.

A estratégia de serviços pode ser considerada a essência de uma estratégia de diferenciação de produtos. Mas para ser bem-sucedida é preciso que ela esteja incluída na cultura da organização. Por isso é que a demanda de produtos de treinamento e informações sobre a gestão de serviços está se expandindo rapidamente. "Programas de treinamento em serviço ao cliente estão novamente na moda. As empresas que promovem seminários oferecem seminários de administração de serviços, e muitas editoras de guias de treinamento estão desenterrando seus produtos de serviços ao cliente e co-

locando-os novamente no topo da lista. Mesmo os programas de extensão nas universidades estão oferecendo cursos de excelência na prestação de serviços" 19 .

O treinamento contínuo é importante para proporcionar a cultura e as habilidades necessárias para que todos os esforços da organização sejam customer focused. Os funcionários devem aprender porque é importante mudar e
17. VAVRA, Terry G. Op. cit.

18. Idem, ibidem, p. 250.

19. ALBRECHT, Karl. Op. cit. 
20. MASON, Barry J. \& MAYER, Moris L. Modern Retailing theory and practice, $6^{a}$ ed. Homewood: IL, 1993.

21. LEVITT, Theodore. Op. cit.

22. Idem, ibidem.

23. Coopers \& Lybrand Deloitte. Op. cit.

24. BERRY, Leonard L. \& PARASURAMAN, A. Op. cit. Maltese-Norma, 1992. reconhecer a excelência dos serviços. $\mathrm{O}$ treinamento precisa ocorrer em todos os níveis e para todas as funções da empresa, provendo um conhecimento detalhado das necessidades dos clientes ${ }^{20}$.

Uma organização necessariamente se internaliza, apesar de também depender de fatores externos. "Dentro" é onde o trabalho se realiza, onde residem as penalidades e os incentivos, onde são feitos os planos e orçamentos, onde ocorrem a engenharia e a fabricação, onde é medido o desempenho, onde estão os amigos e associados, onde as coisas são administradas e administráveis; "fora" é onde "você não pode mudar as coisas"21.

Levitt ${ }^{22}$ alerta que para que essas coisas funcionarem bem e se manterem, há necessidade de treinamento constante de sensibilidade, porque nada se deteriora tão facilmente quanto as práticas e rotinas comportamentais que são e precisam ser institucionalizadas. Essa formalização de rotinas geralmente se degenera em atividades despersonalizadas. Aparentemente, é muito mais fácil agir do que investir tempo, tomar atitudes precipitadas e depois tentar consertar o relacionamento, dizer "vamos analisar o caso, depois o chamaremos de volta". A administração de relacionamento pode ser institucionalizada, mas, no processo, também tem que ser humanizada.

Para o consumidor, muitos dos aspectos de preço são irrelevantes, tendo maior

\section{Figura 1 - Pontos essenciais do marketing interno}

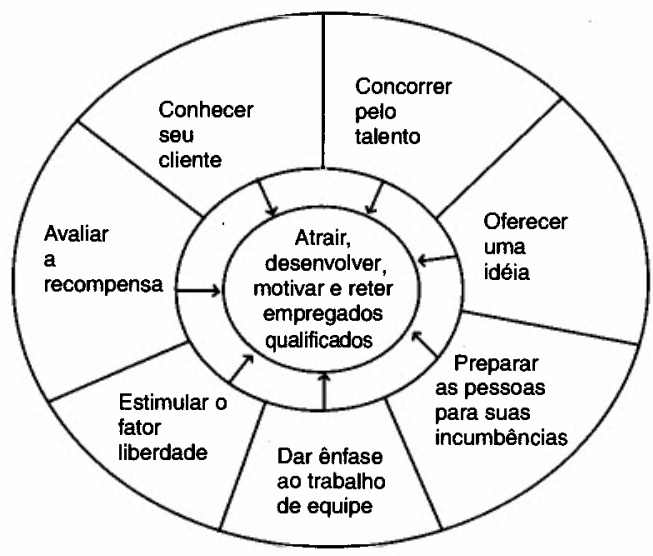

Fonte: BERRY, Leonard L \& PARASURAMAN, A. Servicos de marketing competindo através da qualidade. São Paulo: Maltese-Norma, 1992. relevância a qualidade de elementos tangíveis dos serviços, tais como contato pessoal com o vendedor ou a empresa, por telefone ou na loja ${ }^{23}$.

Berry \& Parasuraman ${ }^{24}$ apresentam sete pontos essenciais na prática do marketing interno, conforme a figura 1.

- Concorrer pelo talento. O contratação do melhor pessoal possível para a realização da tarefa. Muitas companhias têm padrões mal definidos, lastimavelmente baixos para o pessoal contratado. Por que tantos executivos permitem que as pessoas erradas portem a bandeira da empresa diante dos clientes?

- Oferecer uma idéia. A atração, o desenvolvimento, a motivação e a retenção de empregados de qualidade exigem uma idéia muito clara pela qual valha a pena lutar. Um hollerith poderá manter uma pessoa fisicamente no trabalho, mas sozinho não a mantém emocionalmente.

- Preparar as pessoas. O pessoal, em geral, é mal preparado para o serviço. Há o treinamento, mas às vezes é pouco; ou chega tarde demais, ou não é do tipo necessário. Ou, então, o pessoal recebe um bom treinamento na parte técnica, mas não adquire o conhecimento suficiente; ou seja, sabe como fazer, mas não sabe por quê.

- Estimular o fator liberdade. Seres humanos não são robôs, mas muitos administradores os tratam como se fossem, quando usam políticas e manuais de instruções muito densos para limitar rigidamente a liberdade de ação dos empregados na prestação de serviço. Às vezes, um manual de regras destrói a confiança que os empregados têm na chefia, reprime seu desenvolvimento pessoal e a criatividade e abre as portas para que os mais qualificados saiam à procura de trabalho mais interessante.

- Avaliação e recompensa. Os objetivos do marketing interno se frustrarão se o desempenho dos empregados não forem avaliados e recompensados. $\mathrm{O}$ pessoal que trabalha precisa saber que será avaliado pela boa qualidade do que faz e que vale a pena fazer bem.

- Conheça seu cliente. A satisfação dos clientes exige que as pessoas que tomam decisões compreendam primeiro o que eles desejam e quais as suas necessida- 
des. Os empregados também são clientes que compram produtos-trabalho de seus empregadores. O planejamento de produtos-trabalho que atraiam, desenvolvam, motivem e retenham esses clientes internos é algo que demanda sensibilidade em relação a suas aspirações, atitudes e preocupações. A prática da pesquisa de marketing é tão importante no marketing interno quanto no marketing externo.

- Resumo e lista de verificação de atividades. Uma empresa é tão boa quanto seu pessoal, no caso do serviço, principalmente. Um serviço é um desempenho e normalmente torna-se difícil separar o desempenho da pessoa. Se o desempenho não satisfaz as expectativas do cliente, o serviço também não o faz. Investir na qualidade do pessoal é investir na qualidade do produto.

Na verdade, nem sempre a empresa é diretamente culpada pela perda de clientes. Às vezes, eles abandonam uma empresa por razões incontroláveis como mudança de endereço ou uma oferta do concorrente que é impossível cobrir. Mas para capitalizar sobre seu input construtivo, as empresas devem tratar clientes perdidos como oportunidades de aprendizagem. Eles oferecem informações valiosas que podem ser usadas para identificar e remediar problemas, antes que eles afetem outros clientes ${ }^{25}$.

\section{CONSIDERAÇÕES FINAIS}

O setor de serviços da economia compreende as chamadas empresas de serviços, tais como bancos, companhias de aviação e firmas especializadas, incluindo toda a abundância de serviços ligados a produtos, fornecidos pelas indústrias, além dos serviços ligados a vendas, fornecidos pelos varejistas. Portanto, o serviço ao cliente deve deixar de ser arbitrário e passar a ser conscientemente tratado como "fabricação no campo". Quando isso ocorrer, ele será alvo da mesma atenção cuidadosa que a fabricação de produtos recebe. Será cuidadosamente planejado, controlado, automatizado quando possível, verificado no que diz respeito à qualidade e regular- mente examinado para fins de melhora de desempenho e observação das relações do freguês. E o que é mais importante, os mesmos métodos tecnológicos e de economia de mão-de-obra que agora florescem nas operações de produção começarão a ter oportunidades no serviço ao cliente e nas empresas que vendem serviços ${ }^{26}$.

Quanto mais tecnologicamente sofisticado for o produto (automóvel e computador, por exemplo) mais suas vendas dependem da qualidade dos serviços que o acompanham. O comprador de maquinaria automatizada, diferentementemente do comprador no mercado de miudezas, não vai para casa com sua compra a todo risco. Ele espera serviços de instalação, auxílio nas aplicações, peças, reparos e manutenção no pós-compra, desenvolvimentos posteriores e P\&D da firma vendedora, como suporte às necessidades do comprador de permanecer competitivo sob todos os aspectos ${ }^{27}$.

Servir bem é mais do que atender bem. Atender bem é receber bem o cliente, é deixá-lo à vontade para fazer suas queixas e reclamações. Servir bem é dar soluções rápidas e ótimas aos problemas apresentados; é dispor de meios de fazer o cliente sentir-se satisfeito, mesmo que, em alguns casos, tenha que esperar um pouco para ver seu problema resolvido; é oferecer serviços adequados às expectativas do cliente, pois são expectativas, e não coisas, o que as pessoas compram. O objetivo é cumprir as expectativas do cliente, para ganhar sua lealdade e, dessa forma, a clientela continuada, preferivelmente com um nível de satisfação que se refletirá em lucro acima da média.

As expectativas do cliente são os verdadeiros padrões para se avaliar a qualidade do serviço. Compreender a natureza e os determinantes dessas expectativas é essencial para assegurar que a execução do serviço tenha qualidade ${ }^{28}$.

É verdade que nem mesmo um bom serviço ao cliente será capaz de suprir as falhas organizacionais de uma empresa inadequada aos desafios da atualidade, nem de tornar bom um produto ruim. Mas não resta dúvida que um bom produto pode tornar-se mais competitivo se for acompanhado de um bom serviço ao cliente. $\square$
25. VAVRA, Terry G. Op. cit.

26. LEVITT, Theodore. Métodos de linha de produçāo aplicados ao fornecimento de serviços. In: As idéias que revolucionaram a Administraçāo. Prêmio McKinsey - Biblioteca de Administração de Empresas, São Paulo: Abril, 1972, p. 57-66.

27. Op. cit.

28. BERRY, Leonard L. \& PARASURAMAN, A. Op. cit. 